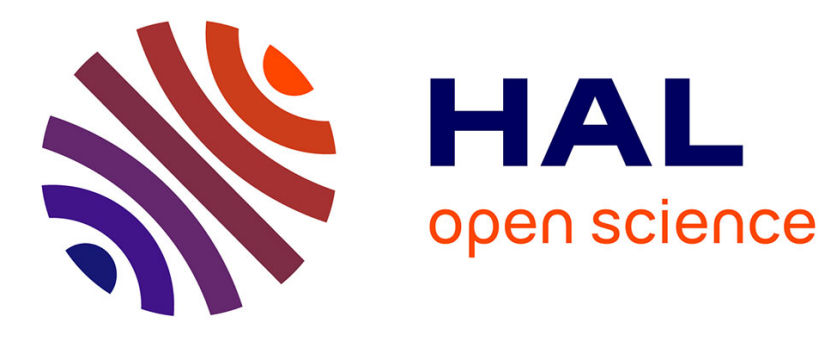

\title{
On the correction capability of a deployed tape-spring hexapod
}

Gwenaelle Aridon, Fabian Blanchard, Arnaud Allezy, Didier Remond, Régis Dufour

\section{- To cite this version:}

Gwenaelle Aridon, Fabian Blanchard, Arnaud Allezy, Didier Remond, Régis Dufour. On the correction capability of a deployed tape-spring hexapod. Mechanism and Machine Theory, 2008, 43 (8), pp.10091023. 10.1016/j.mechmachtheory.2007.07.008 . hal-00381377

\section{HAL Id: hal-00381377 https://hal.science/hal-00381377}

Submitted on 29 May 2019

HAL is a multi-disciplinary open access archive for the deposit and dissemination of scientific research documents, whether they are published or not. The documents may come from teaching and research institutions in France or abroad, or from public or private research centers.
L'archive ouverte pluridisciplinaire HAL, est destinée au dépôt et à la diffusion de documents scientifiques de niveau recherche, publiés ou non, émanant des établissements d'enseignement et de recherche français ou étrangers, des laboratoires publics ou privés.

$$
\text { Copyright }
$$




\title{
On the correction capability of a deployed tape-spring hexapod.
}

\author{
G. Aridon ${ }^{1}$, L. Blanchard ${ }^{2}$, A. Allezy ${ }^{2}$, D. Rémond ${ }^{1}$, and R. Dufour ${ }^{1 *}$ \\ ${ }^{1}$ LaMCoS, INSA-Lyon, CNRS UMR5259, F-69621, France \\ ${ }^{2}$ Alcatel Alénia Space, 100 Bd du midi, BP 99, 06156 Cannes La Bocca cedex, France
}

\begin{abstract}
This paper deals with a hexapod using six rolled tape-springs for space applications. The first part focuses on the prototype design, especially on the blades connecting the tape-springs to the platform. The second part presents the finite element model of the deployed hexapod including pre-stressed and condensed tape-springs. It is compared with the experimental modal testing of the prototype and used as a linear elastic model in the third part, which deals with the correction capability of the hexapod. Jacobian matrices, dexterity and correction capability are defined as performance criteria. Designed to guarantee an equivalent spherical junction, the thin blade configuration does not offer a significant better correction capability compared to the thick blade configuration. Moreover, thick blades provides better deployment repeatability, stiffer behavior. Consequently, the investigation highlights that hexapod kinematics can be ensured by tape-spring flexibility which eliminates the need of connecting blades.
\end{abstract}

Keywords : Tape-spring, Deployable hexapod, Jacobian matrix,

Space-borne observation missions will soon be confronted by many challenges, such as multi-pupil systems designed for free-flyer and Extremely High Resolution systems with large dimensions and demanding requirements for agility ${ }^{1}$. Faced with the high expectations of performance of such missions, deployable structures with adaptive optics have become almost obligatory. Unlike classical hyper-stable structures, deployable structures allow the design of systems larger than the rocket fairing. Moreover, they make it possible to considerably reduce dimensional stability requirements as the position of optical elements can be corrected after deployment and they allow a substantial reduction of mass and inertia, leading to increased agility. However, these lightweight structures have to ensure very rigorous mirror stability during missions, therefore leading to new design considerations. Innovative structural telescope concepts are being studied in order to pave the way for future space telescope design. One of these concepts is based on a deployable hexapod using tape-springs.

Hexapods are highly accurate positioning systems capable of supporting the external payloads often found in various applications (vehicle ride simulators, ground-based telescopes, antennae, medical robots, etc). The wellknown Stewart-Gough platform ${ }^{2}$ uses the length of leg actuators as a variable for controlling the six-degrees-of-

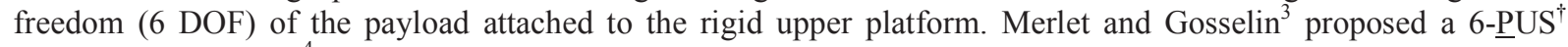
platform manipulator ${ }^{4}$ known as "active wrist" whose major advantage is that the active prismatic joints move vertically in relation to the base and the lower end of the fixed-length legs. Hence the actuators are no longer on legs, thereby reducing inertia. The present investigation focuses on a deployable hexapod based on the StewartGough platform during deployment and the use of the active wrist concept after deployment in order to correct deviations of the platform (see Fig. 1).

Tape-springs are inexpensive and quite easy-to-use, but above all these thin curved strips provide a very simple concept that combines elastic behavior with a natural tendency to seek their deployed configuration. The

\footnotetext{
* Corresponding author: Tel.: +334724389 41; fax: +33472438930

E-mail address: Regis.dufour@insa-lyon.fr

${ }^{\dagger}$ Manipulators are commonly designated by constitutive joints such as prismatic P, universal U and spherical S; the underlined letter indicates the active joint.
} 
deployment of a rigid-panel ${ }^{5}$, Collapsible Rib-Tensioned Surface reflector ${ }^{6}$ and a high-resolution deployable telescope $^{7}$ are applications that use folding tape-springs to form simple self-locking hinges. Several joints have also been developed such as tape-spring rolling hinges ${ }^{8-9}$ and the Aerospatiale "Adele" hinge (patented by Auternaud ${ }^{10}$ ). Besides folding, they can also be used by coiling the strip, recalling the principle of a carpenter's tape measure. In some mechanisms, like thin-walled tubular booms or a deployment cassette for bi-STEM ${ }^{11}$, the cross-section even forms a complete circle with a slight overlap.
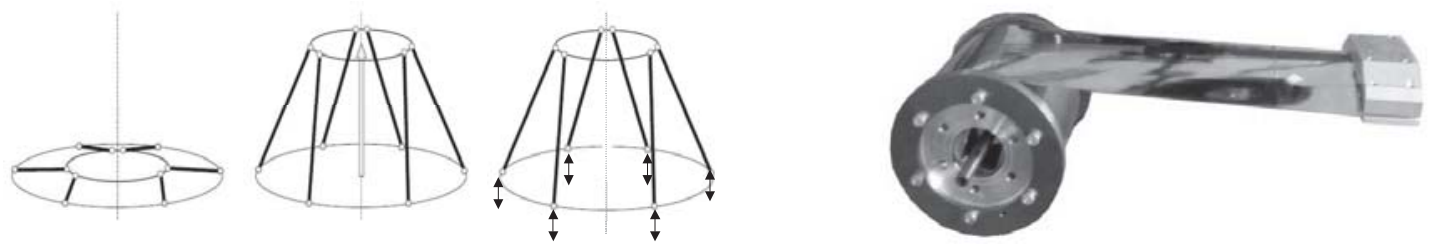

Fig. 1 Stowage, deployment, and correction stages.

Fig. 2 A tape-spring coiling device.

In the application studied here, the tape-spring actuators are composed of a rotating drum in which the tapespring is flattened and coiled (Fig. 2). Such tape-spring coiling devices have been developed and manufactured by IWF TÜ Braunschweig which already used them with motorization in robotic applications ${ }^{12}$. Because of the stress imposed, the tape-spring naturally tends to unroll in order to recover the equilibrium of its curved section. The innovation lies in the fact that these six specific linear actuators are used to deploy the hexapod. In this version of the prototype hexapod, the tape-spring is made of steel.

Dynamic measurements are required to validate new structural models for these unconventional, lightweight and deployable structures. This paper describes experimental and numerical approaches for predicting the dynamic behavior of a tape-spring hexapod, especially for two types of junctions, known as connecting blades, located between the upper ends of the six tape-springs legs and the platform. The prototype is successively equipped with thin and thick connecting blades.

First, the innovative design of the deployable tape-spring hexapod is described. Photogrammetry is used to analyze the deployment repeatability of both configurations.

The second part is dedicated to the modeling of the deployed hexapod. A particular emphasis is given to the use of a non-linear finite element analysis required to pre-stress the tape-springs and to the Craig and Bampton condensation method. The modal analysis carried out on the thin blade hexapod model is compared to the results obtained by subjecting the prototype to experimental modal testing. The hexapod model is then used as a linear elastic model.

The last part deals with the correction capability of the active wrist concept. The linearity of the platform response to actuation is verified experimentally by photogrammetry. Jacobian matrices and dexterity are determined as performance indices. Actuator value sets are calculated to correct platform deployment deviations for both the thin and thick blade configurations. Finally, the choice between the two configurations, determined by stability and/or correction capability is discussed.

\section{Description of the tape-spring hexapod}

\section{A. Hexapod geometry}

Once in orbit, the hexapod is deployed by six tape-spring coiling devices. The release of stored strain energy causes the tape-springs to deploy automatically when the locking system is released. The platform position is then adjusted vis-à-vis its six degrees-of-freedom by using six vertical actuators located under the tape-spring coiling devices. This allows controlling deployment deviations and long-term instabilities (Fig. 1). Optimal performance of the instrument is achieved by an adaptive optics correction stage.

An optimal design study ${ }^{13}$ based on interval analysis has been carried out in order to optimize hexapod correction precision in a defined and guaranteed workspace. It was performed for a theoretical hexapod with ideal spherical and universal joints and infinitely rigid legs. Structural stiffness was examined as a secondary criterion. As a result, this optimally geometric mechanical architecture is lightweight, stiff and designed to be highly fault tolerant. The height of the prototype is $652 \mathrm{~mm}$.

The mobility F of parallel manipulators could generally be calculated from Grübler's formula, written as: 


$$
F=\lambda(n-j-1)+\sum_{i=1}^{j} f_{i}
$$

with $n$ the total number of links including the two platforms, $j$ the total number of joints, $f_{i}$ is the number of DOFs of the $i^{\text {th }}$ joint, and $\lambda$ the dimension of the space in which the manipulator works. For a Stewart-Gough platform designed to be a 6-UPS manipulator, as well as the "active wrist" 6-PUS platform, the previous parameters are: $\lambda=6$, $n=14, j=18, f_{i}=36$, and $\mathrm{F}=6$.

The deployment concept is based on a Stewart-Gough platform with one spherical joint at the top and one universal joint at the base of each leg. The two rotational DOFs of the base junction are given by the coiling of the tape-spring around the hub and a revolute joint that houses the cradle of the coiling mechanism (Fig.3). To ensure that the upper junction behaves like a spherical joint, a revolute joint provides the first rotational DOF and is connected to a metal blade whose flexure provides the second rotational DOF (Fig.4). The last rotational DOF is supplied by the low torsional rigidity of the tape-spring leg. Two hexapod configurations are investigated: the first has thin connecting blades while the second has thick connecting blades. The thick blade configuration almost eliminates a DOF at the upper junction $\left(f_{i}=36\right)$ but uses the flexibility of the tape-springs to guarantee kinematics. The following parts investigate the advantages and drawbacks of both configurations.

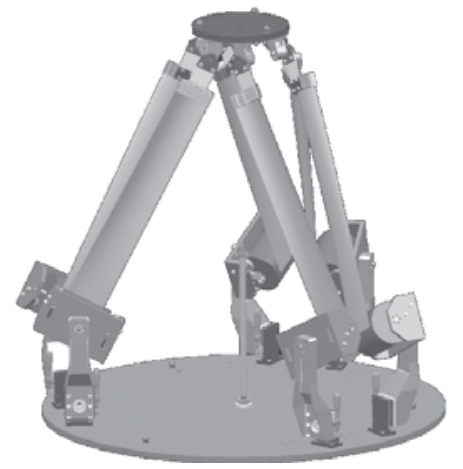

Fig.3 Model of the tape-spring hexapod

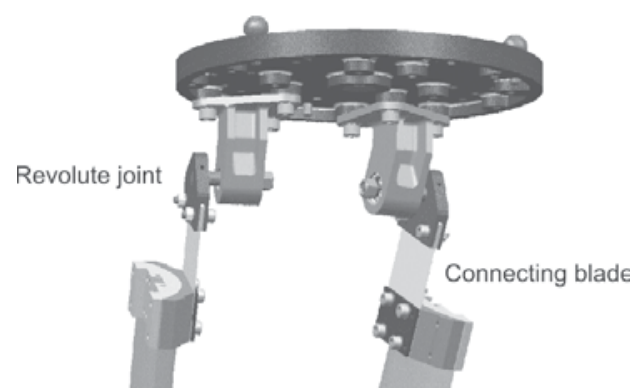

Fig.4 Detail of the upper junction

\section{B. Experimental validation of the mechanical deployment concept}

Deployment repeatability is investigated by using the photogrammetry method. This method has already demonstrated its efficiency in measuring the displacements of lightweight structures ${ }^{14-15}$. It is a microprecision, contactless measurement method and is therefore ideal for characterizing the experimental displacement of the prototype deployment.

In the case studied, the photogrammetry measurements are precise to within 10 micrometers. Accurate measurement requires precise knowledge of the camera's optical characteristics. Based on the triangulation principle, the photogrammetry algorithm converts and maps the flat two-dimensional images back into 3-dimensional objects. Camera fields greater than 30 degrees are recommended to accurately triangulate the coordinates of each target. The prototype was equipped with a set of retro-reflective adhesive targets (see Fig. 5). To reach satisfactory precision, the hexapod deployment was analyzed by using about a hundred images shot from positions distributed uniformly

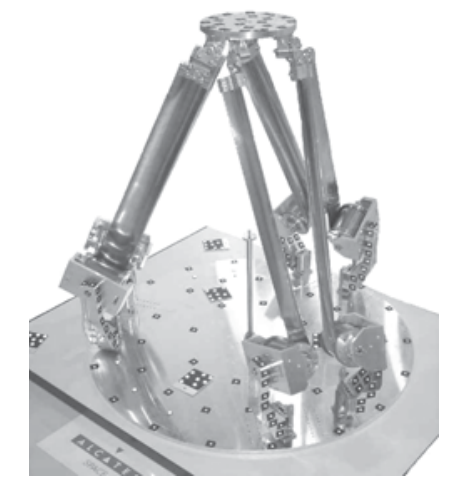

Fig.5 Hexapod prototype with retro-reflective targets around the specimen.

Therefore three-dimensional deployed geometries were recovered from series of photographs of twelve deployments. The results of this set of measurements are reported in terms of rotational and translational deviations following the vertical z-axis in Table 1. 


\begin{tabular}{|c|c|c|c|c|}
\hline \multirow{2}{*}{$\begin{array}{c}\text { Hexapod } \\
\text { configuration }\end{array}$} & \multicolumn{2}{|c|}{ Translational deployment deviations } & \multicolumn{2}{c|}{ Rotational deployment deviations } \\
\cline { 2 - 5 } & Maximal values & Average values & Maximal values & Average values \\
\hline Thin blades & $940 \mu \mathrm{m}$ & $710 \mu \mathrm{m}$ & $2 \mathrm{mrad}$ & $1.3 \mathrm{mrad}$ \\
\hline Thick blades & $240 \mu \mathrm{m}$ & $140 \mu \mathrm{m}$ & $0.7 \mathrm{mrad}$ & $0.42 \mathrm{mrad}$ \\
\hline
\end{tabular}

Table 1. Measurements of deployment repeatability

The deployment deviations of both configurations are included in the $\left[2 \mathrm{~mm} ; 2 \mathrm{~mm} ; 2 \mathrm{~mm} ; 2^{\circ} ; 2^{\circ} ; 3^{\circ}\right]$ workspace guaranteed by the design, leading to the possibility of further corrections of the upper platform position. The deployment repeatability of the thick blade configuration is three times better than with the thin blade configuration. Consequently, the concept of a deployable hexapod with tape-spring legs is possible.

\section{Modal analysis of the deployed hexapod}

\section{A. Model of a flattened pre-stressed tape-spring}

The cross section of the tape-spring is flattened by coiling it around a drum. Modeling such a characteristic requires that the mesh of the tape-spring is as fine as possible to avoid warping of the fournode thin shell elements during the incremental non-linear analysis, and to accurately represent the shape of the first modes considered.

The non-linear finite element (FE) analysis associated with the Newton-Raphson method allows taking into account the strain energy stored by stress stiffening. Boundary conditions are applied to the nodes located at the end in order to flatten the cross section. It is especially important for the mesh to be fine in the flattened part, where the shell elements are the most likely to be warped. Figure 6 shows the deformed tape-spring. The resulting bending moment assumes the influence of the stiffening stress imposed. To confirm the importance of the boundary conditions caused by the coiling device, modal analysis was performed on the finite element model of the nondeformed, flattened without stress (i.e. assuming that the deformed geometry is the initial geometry), and flattened pre-stressed tape-

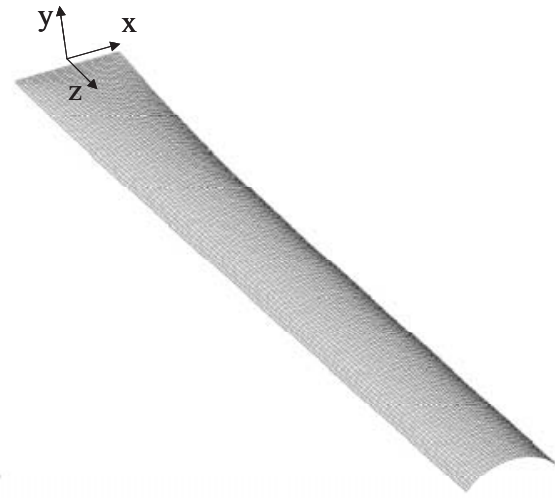

Fig. 6 FE model of a flattened tapespring. spring. The results are presented in Table 2 for a clamped/free tape-spring.

\begin{tabular}{|c|c|c|c|c|}
\hline Mode shape & Non-deformed & $\begin{array}{c}\text { Flattened without } \\
\text { stress }\end{array}$ & $\begin{array}{c}\text { Flattened with } \\
\text { stress }\end{array}$ & \\
\hline $1^{\text {st }} \mathrm{x}$-bending & $51.9 \mathrm{~Hz}$ & $4.21 \mathrm{~Hz}$ & $11.1 \mathrm{~Hz}$ & \\
\hline $2^{\text {nd }} x$-bending & $239 \mathrm{~Hz}$ & $201 \mathrm{~Hz}$ & $203 \mathrm{~Hz}$ & \\
\hline $1^{\text {st }} z$-torsion & $22.2 \mathrm{~Hz}$ & $21.2 \mathrm{~Hz}$ & $99 \mathrm{~Hz}$ & ode \\
\hline $2^{\text {nd }}$ z-torsion & $108 \mathrm{~Hz}$ & $213 \mathrm{~Hz}$ & $231 \mathrm{~Hz}$ & \\
\hline $1^{\text {st }} z$-bending & $252 \mathrm{~Hz}$ & $113 \mathrm{~Hz}$ & $135 \mathrm{~Hz}$ & torsion mode \\
\hline
\end{tabular}

Table 2. Comparison of tape-spring modal contents between the non-deformed, the flattened without stress and the flattened with stress cases, associated with the view of the shape of the two first modes.

The modal content is obviously affected by such a change in the geometry and the stress stiffening caused. Flattening the tape-spring end leads to an inversion of the first modes and significantly decreases the frequency of the x-bending mode. Moreover, in the case where only geometrical change is taken into account, the first torsional mode frequency between the non-deformed case and the deformed case (without stress) remains the same. However, it changes from $21.2 \mathrm{~Hz}$ to $99 \mathrm{~Hz}$ when pre-stress is considered. This therefore highlights the predominant role of 
induced stress. The $1^{\text {st }} \mathrm{z}$-bending mode, the $2^{\text {nd }} \mathrm{z}$-torsion mode and $2^{\text {nd }} \mathrm{x}$-bending mode are not significantly affected by the stress stiffening. Finally, results show that the pre-stressing makes the tape-spring globally stiffer and lead us to deduce that coiling devices use flattening creatively to pre-stress the structure, thereby making it stable.

As a result, six flattened, pre-stressed tape-springs are implemented in the complete finite element model of the hexapod. Once integrated, the boundary conditions applied are equivalent to spherical and rotational joints at the top and the base ends respectively.

\section{B. Model of the tape-spring hexapod}

Modeling the deployed hexapod relies on multi-body and Finite Element Model (FEM) software. The model is composed of two platforms assumed to be rigid bodies and six flexible legs, each leg being modeled with one connecting blade and one flattened tape-spring. Joints constrain the motion of the bodies in the system. The mass properties of the rigid upper platform include those of all the mechanical parts such as screws and ball bearings. Blades and tape-springs are modeled by importing modal contents from external FEM models according to the Component Mode Synthesis (CMS).

The hexapod is a complex structure leading to a large number of degrees of freedom (DOFS). By using the Craig and Bampton reduction method ${ }^{16}$, the computational time and storage costs of the hexapod model have been significantly reduced. This is done as follows:

$$
u=\left\{\begin{array}{l}
u_{I} \\
u_{C}
\end{array}\right\}=\left[\begin{array}{cc}
\Phi_{I N} & \Phi_{I C} \\
0 & I
\end{array}\right]\left\{\begin{array}{l}
q_{N} \\
u_{C}
\end{array}\right\}
$$

where $u_{I}$ and $u_{C}$ are the vectors of interior DOFs and connection DOFs respectively. $I$ and 0 are identity and zero matrices, respectively. The $q_{N}$ vector is composed of the modal variable of the initial mode shapes chosen for the structure clamped at its connection $D O F s$, the latter being contained in truncated modal matrix $\Phi_{\mathrm{IN}}$. Matrix $\Phi_{\mathrm{IC}}$ expresses the interior DOFs as a function of the connection DOFs.

In order to make the Craig and Bampton modal basis suitable for direct use in the simulation of a dynamic system, the Craig and Bampton modes must be ortho-normalized. Another advantage of this procedure is that it permits the introduction of a measured modal damping coefficient by using Basile's assumption ${ }^{17}$. Figure 7 shows the four connection nodes of a connecting blade and the three interface nodes of the upper section of the tape-spring. Three other connection nodes are located at the other end of the tape-spring, i.e. the flattened end.

The Craig and Bampton bases use five mode shapes for each blade and nine for each tape-spring. Therefore changing the base (Eq. 1) reduces the connecting blade model from 1980 to 29 DOFs and the tape-spring from 124230 to 45 DOFs. Finally, considering the entire hexapod, the number of DOFs is 444 , which is about $0.06 \%$ of the initial total number of DOFs.

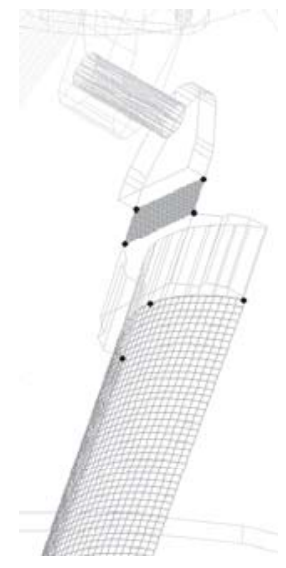

Fig. 7 Connection nodes of an upper joint of the reduced FEM model

\section{Predicted modal analysis of the thin blade configuration}

Table 3 presents the first six natural frequencies predicted and their associated mode shapes. The more flexible mechanical part of the structure is obviously responsible for the first natural modes. The first modes therefore come 
from local modes of twisting and bending thin blades. As can be seen, the torsion mode of the legs (tape-springs + blades) appears close to $77.3 \mathrm{~Hz}$, so obviously torsional coupling occurs between the tape-springs and the thin blades. Since the design of the structure is based on three couples of legs constituted by two tape-springs placed back to back (oriented with opposing curvatures), the bending mode of the legs can be associated with different sets of couplings. These associations of bending modes lead to a tilt, a twist or a pumping mode of the platform. The modal analysis highlights the components that participate in the global motion of the upper platform.

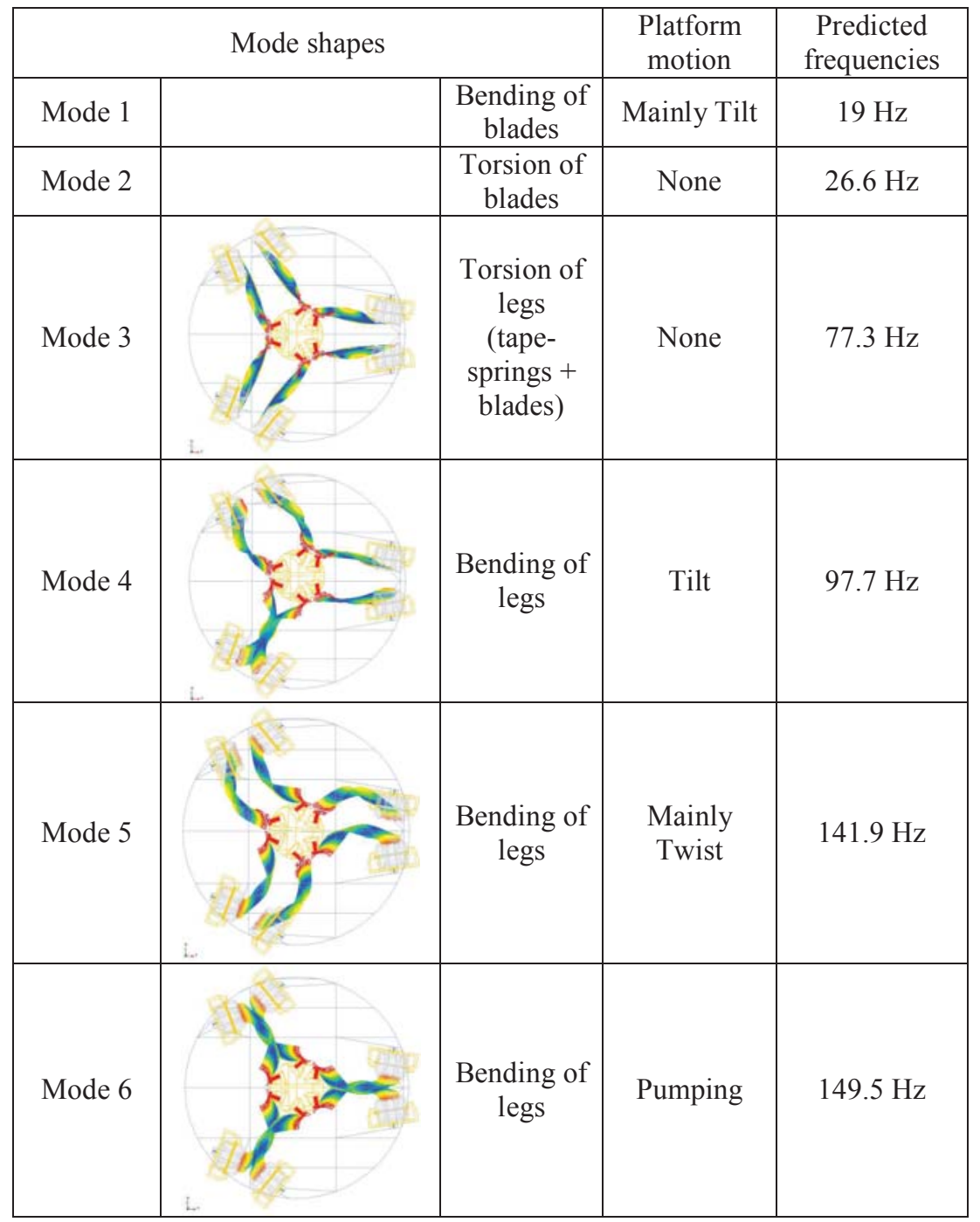

Table 3. Predicted modes and resonant frequencies of the thin blade configuration

\section{Predicted modal analysis of the thick blade configuration}

Based on the previous results, a model of the deployed configuration that replaces the thin blades with thick ones has been formulated. The increase in thickness was from $0.15 \mathrm{~mm}$ to $2 \mathrm{~mm}$, meaning that the new blades were quite rigid. Consequently, the first natural frequency of the deployed hexapod comes from the torsion mode of the tapesprings. Various sets of couplings between tape-spring bending mode shapes are then used to govern the platform's stability (Table 4). 


\begin{tabular}{|c|c|c|}
\hline Mode shapes & $\begin{array}{c}\text { Platform } \\
\text { motion }\end{array}$ & Frequencies \\
\hline Torsion of tape-springs & $/$ & $63.9 \mathrm{~Hz}$ \\
\hline Tape-spring bending & Tilt & $106.6 \mathrm{~Hz}$ \\
\hline Tape-spring bending & Pumping & $120 \mathrm{~Hz}$ \\
\hline Tape-spring bending & Twist & $124.4 \mathrm{~Hz}$ \\
\hline
\end{tabular}

Table 4. Predicted frequencies of the thick blade configuration

The modal prediction shows that dynamic stability is improved in the case of the thick blade configuration. It should be noted that the first numerical frequency increases from $19 \mathrm{~Hz}$ to $63.9 \mathrm{~Hz}$. The global modal content is higher in frequency and more condensed. These results show that this demonstrator exhibits interesting potential for design with high stiffness. A telescope based on this concept should therefore be easily dynamically uncoupled from Attitude and Orbit Control System (AOCS) control loops, which are typically located between 0 and $10 \mathrm{~Hz}$. Thermo-elastic deformations are low frequency disturbances $(<0.001 \mathrm{~Hz})$ and will be quasi-statically corrected thanks to the vertical linear actuators. Uncoupling from mission micro-vibrations (inertia wheels, active cryocoolers, etc.) will be achieved by tailoring the first pumping mode frequency by adequate design of the hexapod constitutive elements, choice of materials and position of junctions.

\section{E. Experimental modal analysis on the thin blade configuration}

The hexapod in its thin blade configuration is deployed and the tape-spring coiling devices are locked. The prototype is mounted on a dynamic shaker and swept sine excited in both the vertical and lateral axes. A set of accelerometers fixed on the upper platform leads to the global motion of the structure: a tri-axial accelerometer, $\mathrm{A}_{1}$, located at the center of the upper platform and two others, $A_{2}$ and $A_{3}$, along the $x$ and $y$ axes (see Fig. 8). Tests were performed in the $0-200 \mathrm{~Hz}$ range. Data were recorded in files with a universal format containing all the set-up characteristics.

To identify the experimental mode shapes, different excitation levels were used: in the vertical direction, three tests were performed with an excitation of magnitudes $0.239 \mathrm{~g}, 1.180 \mathrm{~g}$ and $1.350 \mathrm{~g}$, while three tests were performed in the lateral axis at magnitudes of $0.310 \mathrm{~g}, 0.390 \mathrm{~g}$ and $0.417 \mathrm{~g}$ and two more in the last lateral direction at magnitudes of $0.325 \mathrm{~g}$ and $0.466 \mathrm{~g}(\mathrm{~g}=$ gravity acceleration). The table below presents a comparison between calculated and measured modes with their shapes and excitation directions. Certain natural frequencies appeared only at higher levels of excitation. Furthermore, certain minor nonlinearities were highlighted when the level of excitation was changed.

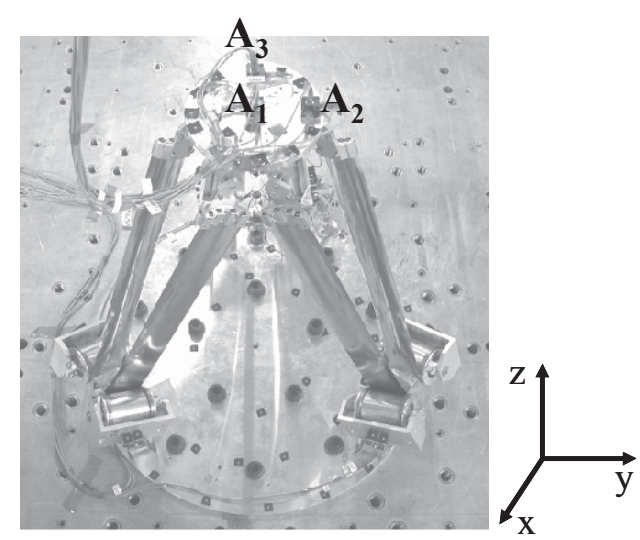

Fig. 8 Accelerometers set-up 


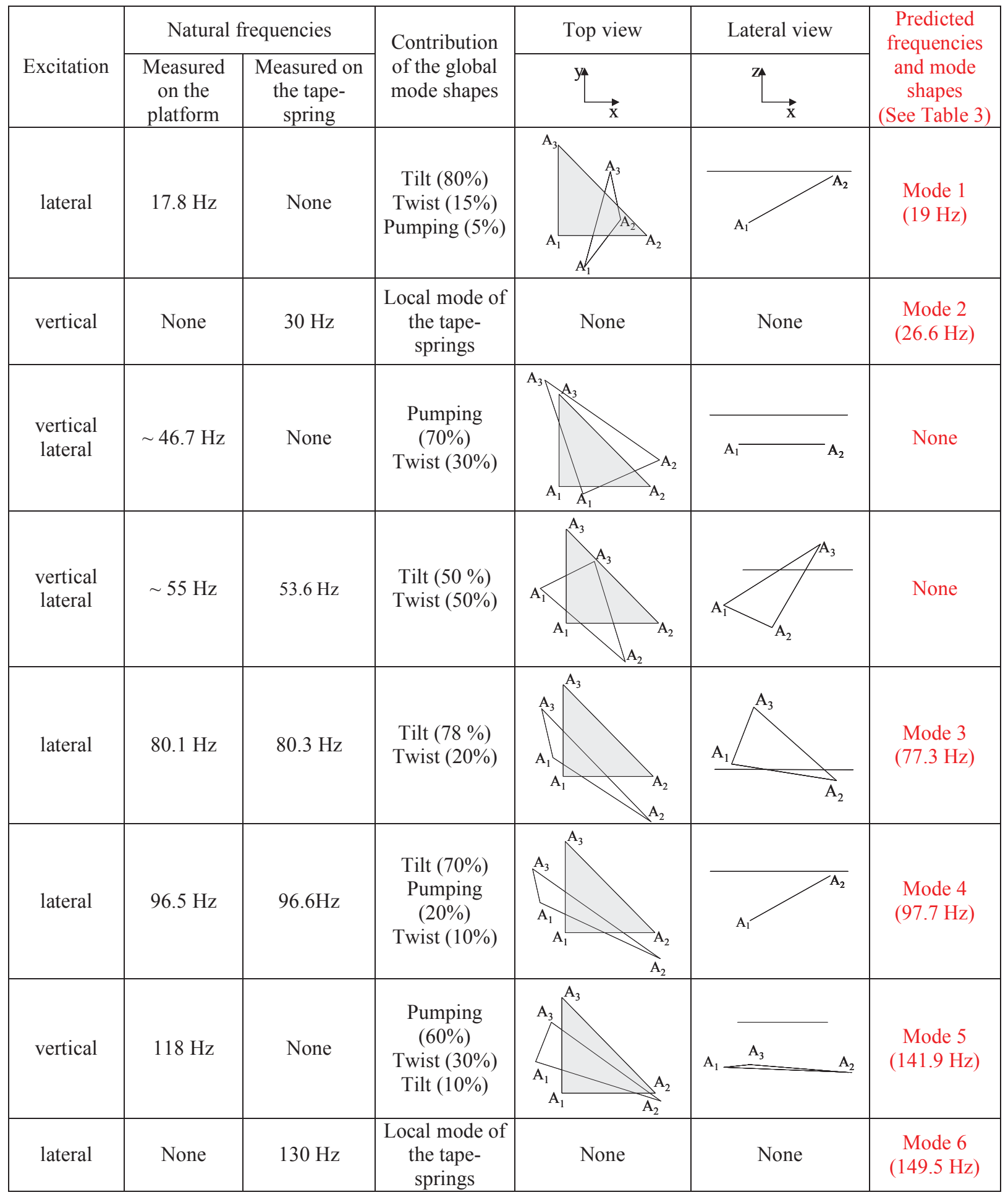

Table 5. Measured natural frequencies and associated mode shapes compared with the predicted modes (initial (grey triangle) and deformed position of the platform plotted from top and side views)

The mode shapes associated with the resonant frequencies were identified. In Table 5, the upper platform is sketched by a triangle whose summits are the locations of the three accelerometers $\mathrm{A}_{1}, \mathrm{~A}_{2}$, and $\mathrm{A}_{3}$. The operational deformation method, which combines the amplitude and phase of the acceleration signals for a fixed forcing 
frequency corresponding to a resonant phenomenon, permits mode shape identification. The use of non-deformed and deformed positions of the triangle plotted by using top and side views permits evaluating the contribution (percentage) of the natural mode shapes of the hexapod in the resonance phenomena under consideration. The tests showed that the resonance behavior of this hexapod depends on the combination of natural mode shapes, which are mostly pumping, tilt, and twist.

Additional couples of mono-axial accelerometers fixed on the tape-spring legs highlighted local mode shapes. Corresponding natural frequencies were found at $30 \mathrm{~Hz}, 53.6 \mathrm{~Hz}, 80.3 \mathrm{~Hz}$, and $130 \mathrm{~Hz}$. The signals with opposing phases of two accelerometers placed on the width of the tape-spring highlighted the torsional modes. The bending modes were identified by comparing two signals from two adjacent back-to-back tape-springs.

Slight misalignments and gaps in the demonstrator introduced disparities in the natural frequencies. For example, measured resonant frequencies at $46.7 \mathrm{~Hz}$ and $55 \mathrm{~Hz}$ were not reproduced in the model. It is assumed that the contact in the clamping devices is not taken into account and the masses of the accelerometers are neglected. Nevertheless, the experimental and numerical modal analyses with thin blades almost match when comparing the predicted and measured mode shapes and natural frequencies.

The model of the deployed hexapod is therefore assumed to be satisfactory and will be used for modal predictions and further investigations on the correction capability of the hexapod as a linear elastic model.

\section{Correction capability of the hexapod}

Once the deployment is achieved, tape-spring coiling devices are locked and then, the deployment deviations and long-term instabilities are corrected along six DOF by using the "active wrist" concept (see Fig. 1 and Fig. 9). In

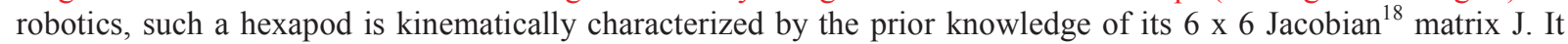
links joint velocities $\dot{q}$ linearly to the generalized velocity $\dot{X}$ of the platform:

$$
\dot{X}=J . \dot{q}
$$

where $X=\left\{U, V, W, \theta_{x}, \theta_{y}, \theta_{z}\right\}^{T}$ represents the platform's generalized coordinates and $\dot{q}$ contains the six vertical velocities of the six actuators located at the base. In other words, when subjected to a control force the vertical variation of an actuator represented by $\delta q$, generates a variation of the platform $\delta X$ :

$$
\delta X=J \delta q
$$

Jacobian matrix $J$ is derived from the inverse kinematics of the hexapod. Thus inverse Jacobian matrix $J^{1}$ leads to variation $\delta q$ as expressed by the following equation:

$$
\delta q=J^{-1} \delta X
$$

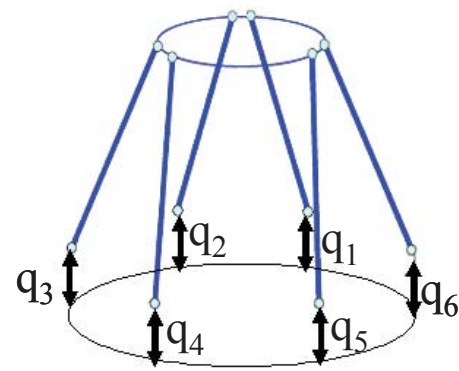

Fig. 9 "Active wrist" concept
The aim of this part is to identify the Jacobian matrix of the hexapod for both configurations, by using the linear elastic hexapod model, and to investigate their capacity to correct the system. The base-plate of the hexapod contains six 1-D stages mounted on $90^{\circ}$ bracket frame. The 1-D stages support the bottom junctions and permit the vertical displacements of the locked coiling mechanisms with a maximal $16 \mathrm{~mm}$ stroke and a 20 $\mu \mathrm{m}$ resolution.

\section{A. Thin blade configuration: Measured and predicted responses of the platform to $q_{1}$}

Three successive $q_{1}$ displacements $(-600 \mu \mathrm{m},-400 \mu \mathrm{m}$, and $-200 \mu \mathrm{m})$ were successively applied to a single $1-\mathrm{D}$ stage. The response of the platform was measured by using the photogrammetry method described in Section II-B and presented in Fig.10. Its comparison with simulations from the linear elastic model confirms the linear relationship between the displacements $\delta q$ of the 1-D stages, and the motion $\delta X$ of the platform. Residual 
hysteretic behavior on the $U$ deflection can be noticed. There is no correlation between the measured and predicted $\mathrm{U}$ and $\mathrm{V}$ deflections, probably because of backlashes or friction in the joints. The accuracy obtained on these translational and rotational displacements was about $30 \mu \mathrm{m}$ RMS and 34 mrad RMS respectively.
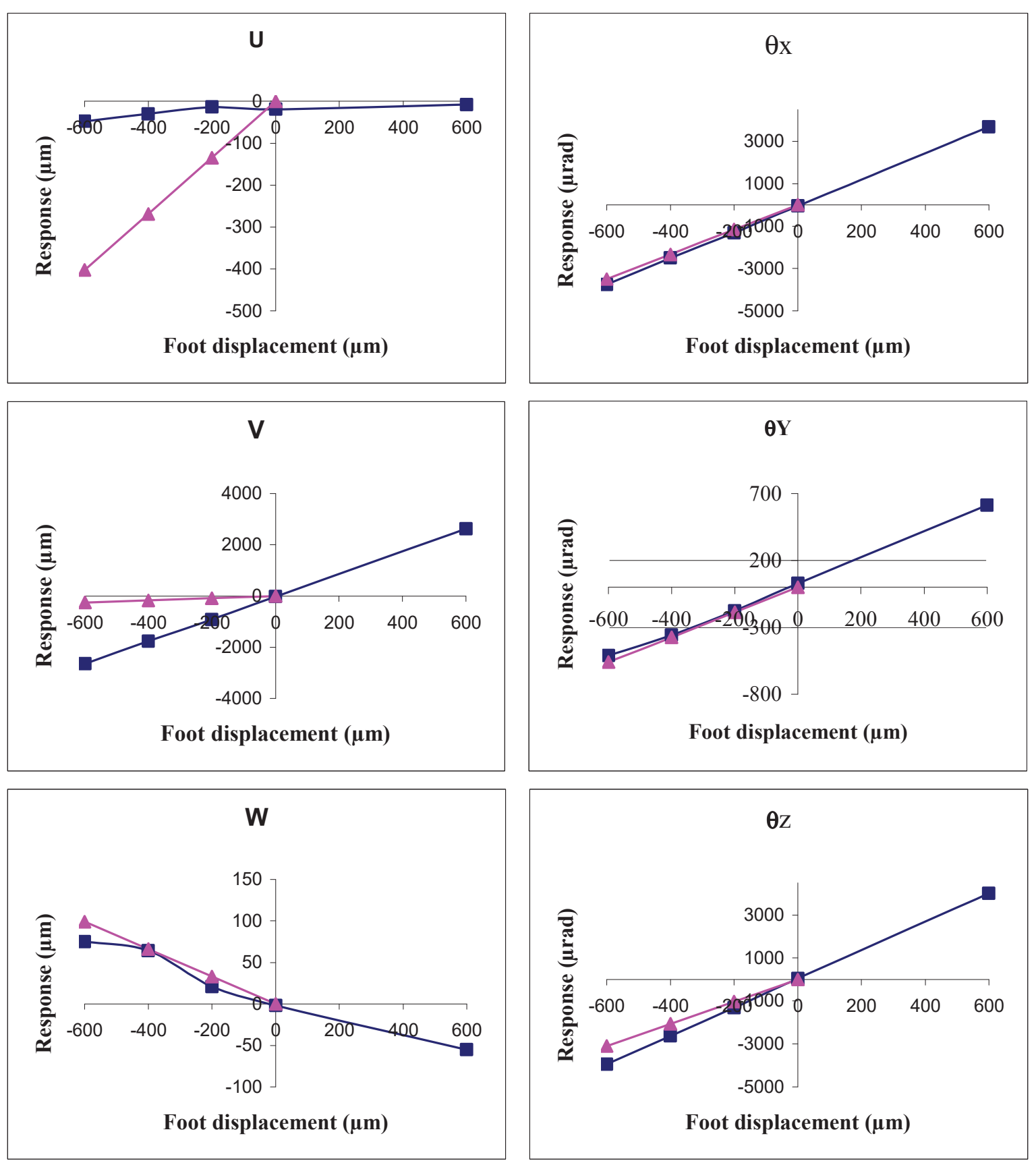

Fig. 10 Predicted ( 4 ) and measured (•) responses of the 6 DOFs of the platform

\section{B. Identification of the theoretical Jacobian matrices}

Thanks to Eq.3, the predicted Jacobian matrices of the tape-spring hexapod are established for both configurations by predicting the platform response to the six successive vertical actuator displacements (see Eq. 5 
and 6). The six columns of the Jacobian matrices correspond to the six 1-D stages of the hexapod while the six rows represent the generalized coordinates $\left\{U, V, W, \theta_{x}, \theta_{y}, \theta_{z}\right\}$ of the platform's DOFs.

$$
\begin{aligned}
J_{\text {predicted }}^{\text {thin }} & =\left[\begin{array}{llllll}
0,672 & 0,672 & -0,712 & 0,040 & 0,040 & -0,712 \\
0,434 & -0,434 & 0,365 & 0,799 & -0,799 & -0,365 \\
-0,166 & -0,166 & -0,166 & -0,166 & -0,166 & -0,166 \\
5,163 & -5,163 & -3,390 & 1,773 & -1,773 & 3,390 \\
0,934 & 0,934 & 4,004 & -4,938 & -4,938 & 4,004 \\
5,831 & -5,831 & 5,831 & -5,831 & 5,831 & -5,831
\end{array}\right] \\
J_{\text {predicted }}^{\text {thick }} & =\left[\begin{array}{lllllll}
0,671 & 0,671 & -0,705 & 0,034 & 0,034 & -0,705 \\
0,427 & -0,427 & 0,368 & 0,795 & -0,795 & -0,368 \\
-0,162 & -0,162 & -0,162 & -0,162 & -0,162 & -0,162 \\
5,070 & -5,070 & -3,351 & 1,719 & -1,719 & 3,351 \\
0,942 & 0,942 & 3,920 & -4,862 & -4,862 & 3,920 \\
5,719 & -5,719 & 5,719 & -5,719 & 5,719 & -5,719
\end{array}\right]
\end{aligned}
$$

Figure 11 shows the location of the actuators in relation to the frame of reference $x y$. The six values obtained for row $W$ (i.e. the third row) of $J$ (see Eq.5 for example) are obviously identical since each foot stroke produces the same level of elevation. The other responses $U, V, \theta_{x}, \theta_{y}$, and $\theta_{z}$ depend on the location of each actuator compared to the frame of reference $x y$. Columns $2,3,4,5$, and 6 can be deduced from the first column by using a rotation matrix.

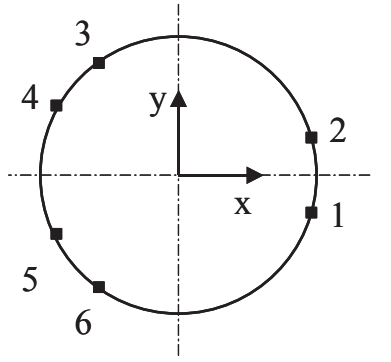

Fig. 11 Location of the actuators

The analytical formulation of the Jacobian matrices is described in detail in papers ${ }^{19}$ and ${ }^{20}$, which consider rigid leg hexapods with correction provided by vertical 1-D stages located at the base.

\section{Dexterity}

A large dimension along a given axis indicates a large amplification error. It is therefore necessary to quantify this error amplification factor, called condition number ${ }^{21}$ and defined as:

$$
\kappa(J)=\frac{\sigma_{\max }}{\sigma_{\min }}
$$

$\sigma_{\max }$ is the largest singular value and $\sigma_{\min }$ is the smallest singular value of matrix J. The singular value is the square root of the eigenvalues of $\left(J^{-1}\right)^{T} J^{-1}$. The condition number of $\mathrm{J}$ is the square root of the ratio between the largest and the smallest eigenvalues of $\left(J^{-1}\right)^{T} J^{-1}$.

$$
1 \leq \kappa(J)<\infty
$$

Matrix $J$ is said to be well conditioned when the condition number approaches 1 . On the other hand, as the condition number approaches infinity the matrix is said to be ill-conditioned. i.e., close to singularities. 


$$
\kappa_{\text {thin }}=35.21 \quad \text { and } \quad \kappa_{\text {thick }}=35.37
$$

$\kappa$ is an indicator of the quality of performance of a manipulator with respect to force and velocity transmission. Furthermore, it qualifies the dexterity of a mechanism which can be considered as its ability to perform small actuator vertical displacements at a specified position of its workspace. The predicted condition numbers show that the deployed tape-spring hexapod is far from singularities for both configurations. $\boldsymbol{\kappa}_{\text {thin }}$ and $\boldsymbol{\kappa}_{\text {thick }}$ are very similar.

\section{Illustration of the theoretical correction capability of both configurations}

Knowledge of the Jacobian matrices is used to characterize the hexapod's behavior kinematically. An arbitrary position of the deployed platform center is considered with deviations close to the measured maximal deployment deviations. Let the generalized coordinate vector of the platform be:

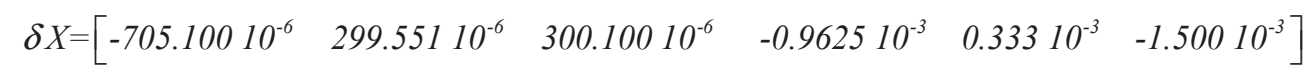

In this range, the hexapod behavior is linear and using equation 4 leads to the prediction of the six 1-D stage displacements $\delta q$ required correcting the upper platform position. Sets of values are calculated for both thin and thick blade configurations and compared to $\delta q_{\text {rigid }}$. The latter originates from a theoretical hexapod with ideal spherical and universal joints and infinitely rigid legs. The table below presents the actuation sets with their associated error percentages.

\begin{tabular}{|c|c|c|c|}
\hline \multirow{2}{*}{$\begin{array}{c}\text { Rigid configuration } \\
\delta q_{\text {rigid }}(\mu \mathrm{m})\end{array}$} & \multicolumn{3}{|c|}{ Percentage of error from the rigid configuration (\%) } \\
\cline { 3 - 4 } & Thin configuration & Thick configuration \\
\hline$q_{1}$ & -676.5 & -0.114 & -1.330 \\
\hline$q_{2}$ & -528.2 & -0.030 & -0.913 \\
\hline$q_{3}$ & 33.3 & 0.013 & -0.943 \\
\hline$q_{4}$ & -43.5 & -0.065 & -1.294 \\
\hline$q_{5}$ & -390.0 & -0.128 & -1.557 \\
\hline$q_{6}$ & -205.2 & 0.001 & -0.745 \\
\hline
\end{tabular}

Table 6. 1-D stage displacements $\delta q$ of the theoretical rigid leg configuration compared with the thin and thick blade configuration models.

At first glance it appears that both configurations offer quite similar correction capabilities (see Table 6). The thin blade configuration is closer to the rigid configuration than the thick blade configuration. The thick blade configuration requires slightly higher correction amplitude because it uses the flexibility of the tape-springs to guarantee the hexapod's kinematics, i.e. ensure the two DOFs needed to create an equivalent spherical upper joint (see Section II.A). Nevertheless, the resulting correction capability is not significantly reduced with the thick blade configuration.

For an optical application, the accuracy required by the active wrist correction should be closed to the adaptive optic correction capability, i.e. closed to the size of the wave fronts observed by the instrument (inferior to the micron for visible wave fronts).

\section{Conclusion}

This paper presented preliminary investigations on the stability and payload position capabilities of a deployable tape-spring hexapod system. Two configurations of the upper junctions with thick and thin connecting blades were considered. The discussion focused on the need to have sufficient DOFs at the upper junctions to obtain good correction range capability and secure deployment. 
The photogrammetry method showed that the deployment deviations for both configurations were within acceptable limits as they occurred within the hexapod's workspace. Nevertheless, the predicted thick blade configuration led to safer deployment.

Tape-spring finite element models proved that the coiling devices use the flattening in a creative manner to prestress the structure and to make it stiffer. The proposed model of the deployed tape-spring hexapod was validated experimentally by comparing predicted and measured natural frequencies. This double approach permits understanding the global behavior of the hexapod and especially its mode shapes. What is more, its dynamic behavior is greatly influenced by the stiffness of the connecting blades. Hence the thick blade configuration is stiffer, leading to the assumption of better accuracy and stability of the payload position.

The last part dealt with the correction capability of the active wrist concept of the hexapod. The aim was to see how the hexapod's correction capabilities were affected by changing junctions.

The linearity of the platform's response was verified experimentally by photogrammetry in an actuation range of [$600 \mu \mathrm{m} 600 \mu \mathrm{m}]$. The Jacobian matrices of both configurations were identified by using linear finite element models formulated previously. Dexterity was evaluated, showing that the hexapod is far from reaching singularities, whatever the thickness of the connecting blades. The Jacobian matrices permitted calculating the actuation required to correct a platform deviation by using an inverse approach. Thin and thick blade configurations had quite similar correction capabilities. The thin blade configuration was initially designed to have equivalent spherical joints, but the thick blade configuration proved that the tape-springs were able to provide the required DOFs without significantly affecting the hexapod workspace.

As a result, by eliminating a DOF at the upper junction, the thick blades permitted reliable deployment and offered better modal content, i.e. accurate positioning for the same kinematics capabilities. Discussion on both configurations showed that it was not necessary to introduce the additional DOF, by using flexural blades, to be compliant with active wrist kinematics. This function was provided by the flexibility of the tape-springs. Nevertheless, attention is required to keep the loads generated within the limits of the critical buckling loads of the tape-spring on the one hand, and those of the load capability of the 1-D stages and joints.

The next step will consist in investigating the control required for such an innovative hexapod, by implementing the Jacobian matrices.

\section{References}

${ }^{1}$ W. Keith Belvin, "Advances in Structures for Large Space Systems“, Space 2004 Conference and Exhibit, AIAA 20045898, San Diego, California, 28 - 30 September 2004.

${ }^{2}$ D. Stewart, “A platform with six degrees of freedom“, Proc. Instn Mech.Engrs, 180-1(15):371-386, 1965.

${ }^{3}$ Merlet JP and Gosselin C.M., "New architecture for a six-degree-of-freedom parallel manipulator", Mechanism \& Machine theory, 26, 77-90, 1991.

${ }^{4}$ J.-P. Kim and J. Ryu, "Closed-Form Dynamics Equations of 6-DOF PUS Type Parallel Manipulators", ASME Design Technical Conferences, 26th Biennial Mechanisms Conference, Baltimore, MD, September 10-13, 2000.

${ }^{5}$ Seffen, K. A. and Pellegrino, S., "Deployment of a rigid panel by tape-springs", Report CUED/DSTRUCT/TR168, Department of Engineering, University of Cambridge, UK, 1997.

${ }^{6}$ C.Y. Lai and S. Pellegrino, "Design and Testing of a $1.5 \mathrm{~m}$ Offset CRTS Demonstrator", CUED/D-STRUCT/TR193, Department of Engineering, University of Cambridge, UK, 2001.

${ }^{7}$ G. Pica, L. Ciofaniello, S. Mattei, M. Rosaria Santovito, R. Gardi, "High resolution deployable telescope for satellite application", Proceedings of Spie's Remote Sensing Europe 2003.

${ }^{8}$ A. M. Watt and S. Pellegrino, "Tape-Spring Rolling Hinges", Proceedings of the 36 Aerospace Mechanisms Symposium, Glenn Research Center, May 15-17, 2002.

${ }^{9}$ S. Pellegrino, E. Kebadze, T. Lefort, and A.M. Watt, "Low-Cost Hinge for Deployable Structures", CUED/DSTRUCT/TR202, Department of Engineering, University of Cambridge, UK, 2002.

${ }^{10}$ Self-motorized antifriction joint and an articulated assembly such as a satellite solar panel equipped with such joints, Auternaud et al. US Patent No. 5,086,541, Feb. 11, 1992

Self-motorized antifriction joint and an articulated assembly such as a satellite solar panel equipped with such joints, Auternaud et al. US Patent No. 5,086,541, Feb. 11, 1992

${ }^{11}$ Diana A. Galletly, Simon D. Guest, "Bistable composite slit tubes. I. A beam model”, International Journal of Solids and Structures 41 4517-4533, 2004.

${ }^{12}$ J. Hesselbach, M. B. Helm, H. Kerle, S. Soetebier, M. Krefft, “A parallel robot with Spread-Band Elements”, Proceedings of the 32nd International Symposium on Robotics, 19-21 April 2001

${ }^{13}$ Blanchard L., Falzon F., Dupuis J., Merlet J.P., "Deployable hexapod using tape-springs”, Disruption in Space, ESA/CNES Symposium, Marseille, June 2005. 
${ }^{14}$ Dharamsi, U. K., Evanchik, D. M., and Blandino, J. R., "Comparing Photogrammetry with a Conventional Displacement Measurement Technique on a Square Kapton Membrane," AIAA paper 2002-1258, April 2002.

${ }^{15}$ Black, Jonathan T., "Photogrammetry and Videogrammetry Methods Development for Solar Sail Structures ", NASA2003-cr212678, http://hdl.handle.net/2002/12085, Dec-2003

${ }^{16}$ Craig R.R, Jr., Bampton M.C.C., "Coupling of substructures of dynamic analysis“, AIAA Journal, 6(7), 1313-1319 (1968)

${ }^{17}$ Gjika K., Dufour R., Ferraris G., "Transient response of structures on viscoelastic or elastoplastic mounts: prediction and experiment", journal of Sound and Vibration, 198(3), 361-378, 1996.

${ }^{18}$ Merlet J.P., "Parallel Robots", Kluwer Academic Publisher, Dordrecht, 2002.

${ }^{19}$ Lazarevic Z., "Feasibility of a Stewart Platform with Fixed Actuators as a Platform for CABG Surgery Device”, Master's Thesis, Columbia University, Department of Bioengineering

${ }^{20}$ Hopkins B. R. and Williams II R. L., "Kinematics, Design and Control of the 6-PSU Platform", Industrial Robot, Vol. 29, No. 5, pp. 443-451, 2002

${ }^{21}$ Merlet J.P., "Jacobian, Manipulability, Condition Number, and Accuracy of Parallel Robots”, Journal of Mechanical

Design, ASME, Vol. 128, 199-206, 2006. 